\title{
La construcción del sí mismo. El caso de la publicidad electoral: "La fuerza de Atilio» (Frente para la Victoria, 20II)
}

Betina Kesler y Valentina Jara

Facultad de Humanidades y Ciencias, UNL

\section{Resumen}

La publicidad, en general, visibiliza, pone en superficie e, incluso, construye una necesidad. La publicidad audiovisual, en particular, utiliza estrategias formales del cine y el documental en esta construcción. En este artículo se abordará el modo en que las publicidades electorales de la campaña del Frente para la Victoria (FPV) (2OII) crean la necesidad a partir de estrategias formales $y$, a su vez, a partir de la puesta en funcionamiento de un nosotros pretendidamente inclusivo que configura e instaura un «ser argentino». Sin embargo, en este nosotros puede leerse el otro término del par dicotómico en tanto ese otro es construido discursivamente por una hegemonía y es tematizado a partir del empleo (formal) de ciertos estereotipos. En este sentido, los spots publicitarios del FPV (20II) operan en la configuración de un nosotros partidario que supone un lector-consumidor que naturaliza y reproduce lógicas dominantes.

Palabras clave:

publicidad electoral, discurso dominante, estereotipia. 


\section{Abstract}

Advertising, in general, makes visible, puts on surface and even builds a need. Audiovisual advertising, in particular, employs cinematographic and documentary formal strategies in this construction. This article will

Keywords:

electoral advertising, dominant discourse, stereotype. address the way in which the "Frente para la Victoria" (FPV) campaign ads (2OII) create needs through formal strategies and, at the same time, configure and establish a «being Argentine» through the commissioning of a supposedly inclusive "we». However, in this weit is possible to read the other term of the dichotomous pair, that other which is discursively constructed by a dominant hegemony and thematizedthrough the (formal) use of certain stereotypes. In this sense, 2OII FPV spots operate in the setting of a we supporter who presupposes a reader-consumer who naturalizes and recreates the dominant logic.

\section{Presentación}

Este artículo se construye sobre la base de dos trayectorias individuales.

La primera corresponde a la ponencia de una de las autoras de este artículo, publicado este año en las Actas del IX Congreso Argentino y IV Congreso Internacional de Semiótica de la Asociación Argentina de Semiótica. Derivas de la semiótica, teorias, metodologías e interdisciplinaridades. En esta publicación — denominada «La industria cinematográfica argentina (1933-1944). Entre la innovación tecnológica y la reproducción simbólica»— se instala un recorrido hacia atrás en el tiempo y en el sentido. Un abordaje retrospectivo que nos sitúa en los inicios del cine sonoro argentino y nos permite identificar algunas trayectorias del sentido a la significación desde donde interpretarlo como fenómeno social y cultural asociado al proyecto nacional demarcado en el Preámbulo de la Constitución de la Nación Argentina de 1853.

La segunda corresponde al informe de lectura presentado por la otra autora de este artículo en el marco del Seminario de Semiótica II: narrativas audiovisuales de la carrera de Letras de la Facultad de Humanidades y Ciencias de la UNL. Allí, ha abordado el texto publicitario a partir de una hipótesis general y una serie de hipótesis subsidiarias que argu- 